\title{
Nerve Fiber Layer Defects Imaging in Glaucoma
}

\author{
Kubena T., Kofronova M. And Cernosek P. \\ Glaucoma service \\ U zimniho stadionu 1759 \\ Czech Republic
}

\section{Introduction}

Glaucoma is in the group of neurodegenerative diseases. A characteristic of this disease is glaucoma neuropathy which is caused by a loss of ganglion cells. In a healthy eye there is a vital optic nerve head and a thick layer of nerve fibres. With a glaucoma patient there are various stages of defects in nerve fibre layer. A subjective examination of the nerve fibre layer belongs in routine glaucoma examinations. It is beneficial for early glaucoma diagnostic. For documentation and follow-up examinations it is useful to make special adjusted red free photos to compare them with these baseline photos. This paper shows a step by step examination nerve fibre layer, its digital photo documentation, picture processing and archiving. Practical benefit of the adjusted red free photos of nerve fibre layer is highlighted in two interesting cases.

\section{Nerve fibre layer defects and how to diagnose them}

In a healthy eye the nerve fibre layer can be seen as silky and clear with fine strips in red free digital photos (Figure 1). The nerve fibre layer is thickest near to the optic nerve head, especially in the inferior part, slightly thinner is in the superior part. In the temporal part, which includes a maculopapillar bundle, nerve fibre layer is very silky, stripy but no perfectly clearly visible. In the nasal part it is difficult to detect the nerve fibre layer because in this area is naturally thin. In the temporal part of the macula a horizontal line connecting superior and inferior nerve fibre layers can be found. Some vessels are also very helpful in detecting nerve fibre layers. In a healthy eye vessels are overlapped of the nerve fibre layers like several veils.

In a routine ophthalmologic examination we used to provide a biomicroscopy with a Volk 65 or 90 dioptres lens. To detect the nerve fibre layer we use a red free light which reflects from nerve fibre layer and make visible its characteristic stripy structure. In location of a nerve fibre layer loss the red free light goes through the retina and is reflected from the retinal pigment epithelium. Such places are darker with loss of its characteristic stripping, widening from optic disc to periphery like a comet. Blood vessels are darker in the defects and vessels have sharp reflexes. Defect of nerve fiber layer bellow the optic disc (Fig 2a). corresponds with defect / scotoma/ in the upper part of visual field of the same eye (Fig $2 b)$. 


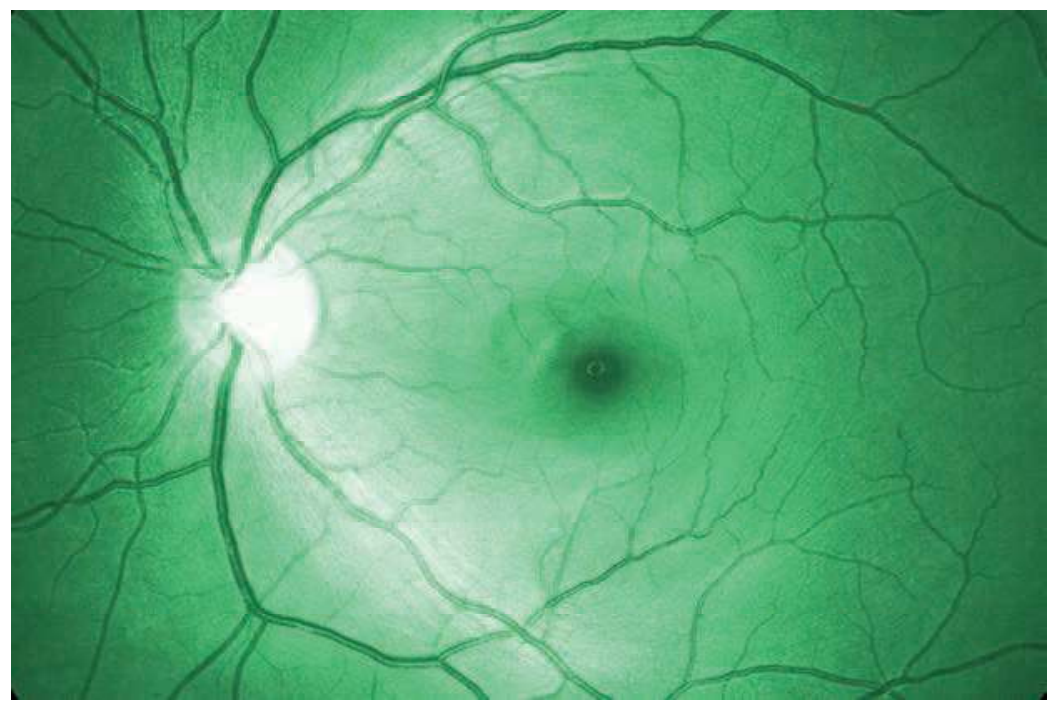

Fig. 1. Nerve fibre layer in healthy eye

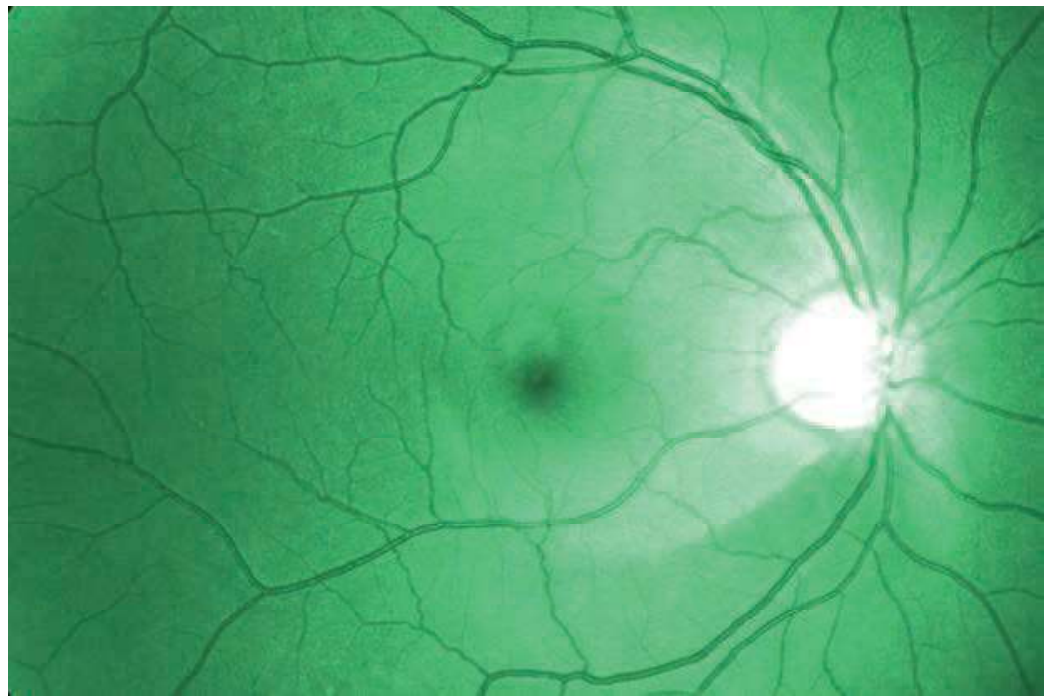

Fig. 2a. Nerve fibre layer defect bellow the optic disc 


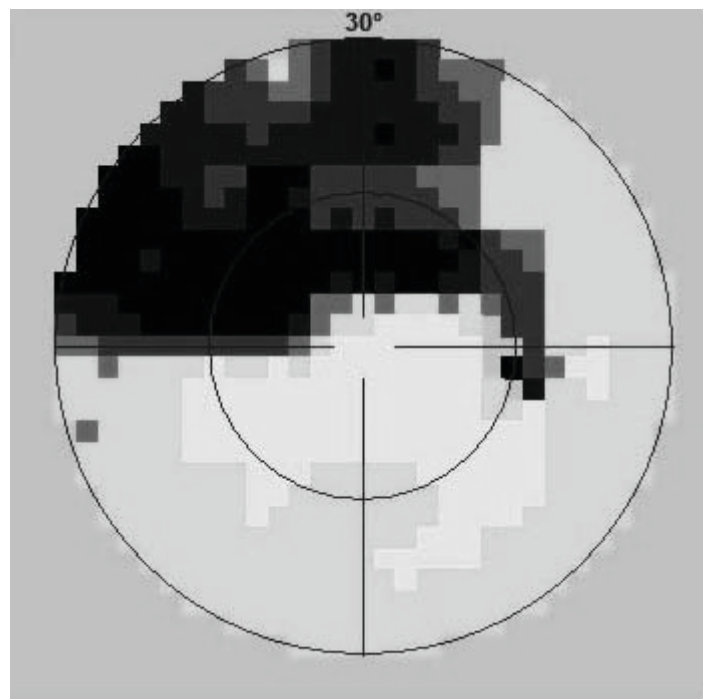

Fig. 2b. Defect / scotoma/ in the upper part of visual field

Small focal defects width of few retinal vessels do not cause visual field defects. This stage of glaucoma is called preperimetric stadium. For that reason the focal defects are very important and helpful in the diagnosis of early stage of glaucoma (Fig 3).
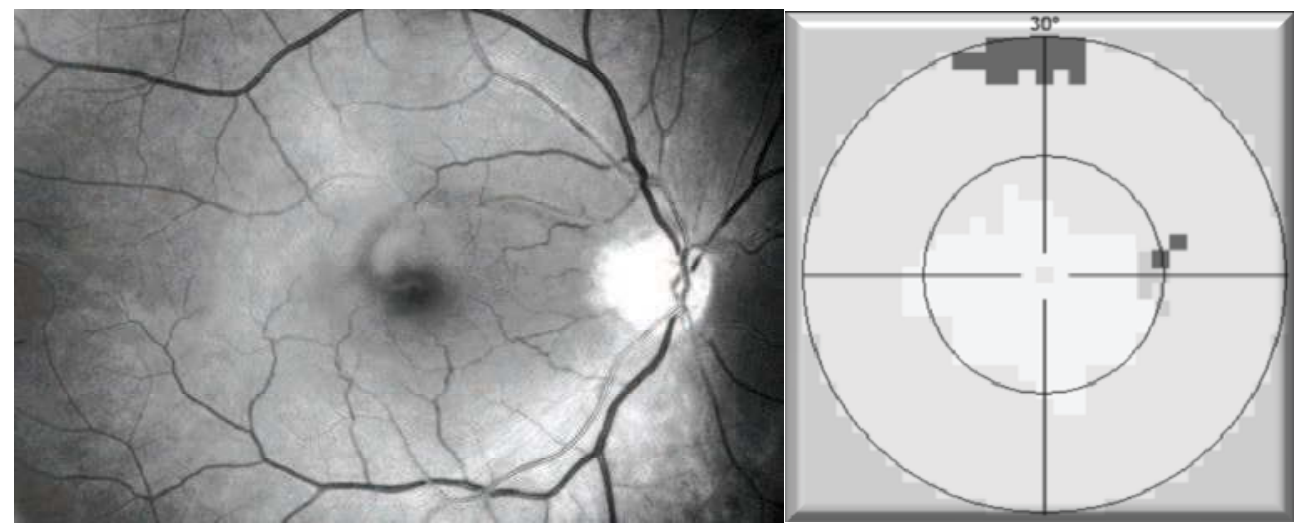

Fig. 3. Focal defect in nerve fibre layer in upper part of maculopapillar bundle with normal visual field of the same eye.

With glaucoma progression nerve fibre layer defects getting darker and enlarge from strip to wedge form. Than first visual field defects begin to appear. This stage of glaucoma is called perimetric stadium. Visual field defects usually begin in the nasal area of the visual field close horizontal line and are known as a Ronne's nasal step (Fig 4). The wedge defect of the nerve fibre layer between 12 to 2 clock corresponds with her visual field defect bellow nasal horizontal line. The focal defect of her nerve fibre layer in 5 clock has not induce a visual field scotoma yet. 

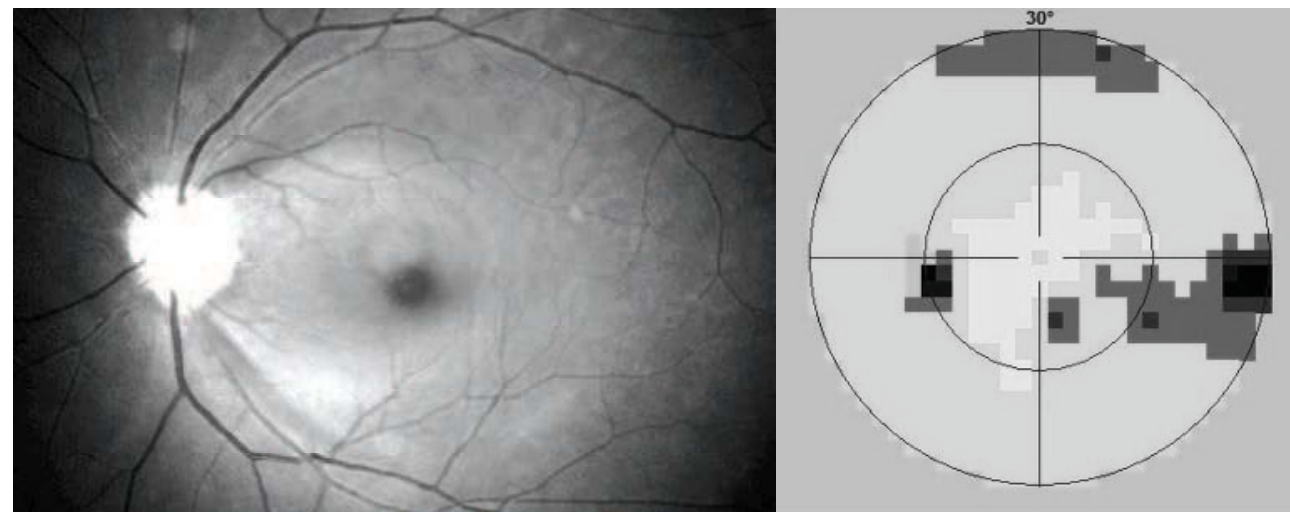

Fig. 4. Wedge defect in 12-2 clock correspond with lower Ronne's nasal step of the visual field the same eye. Focal defect in 5 clock with normal upper part of visual field.

With glaucoma progression nerve fibre layer defects enlarge and visual field defects expand to paracentral part and lasts in blind spot area. Wedge defects well correspond with visual field defects (Fig 5).
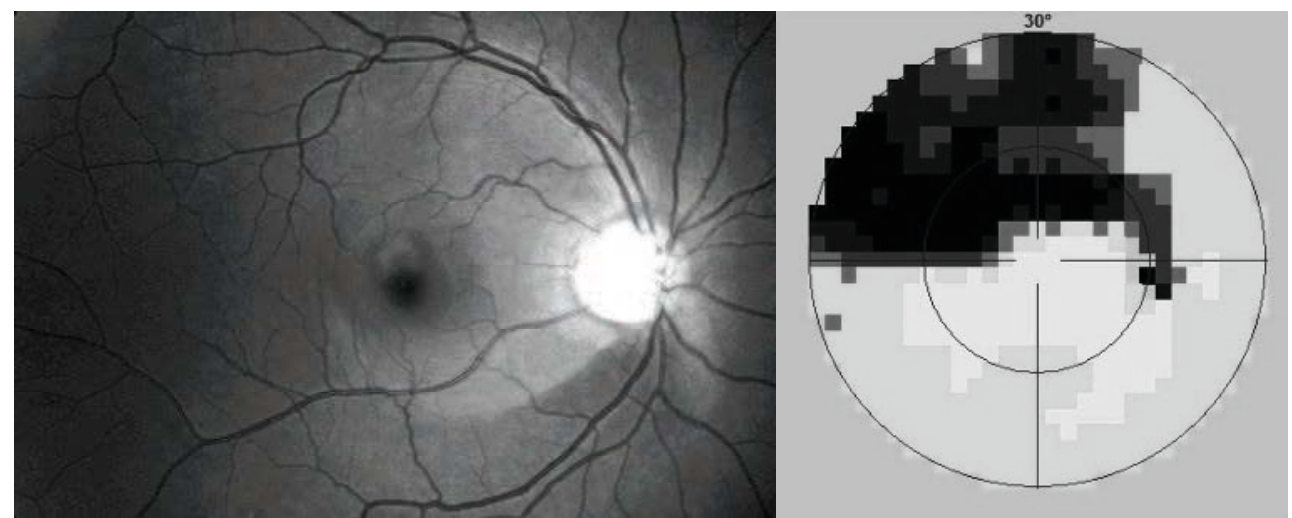

Fig. 5. Wedge defect of nerve fibre layer in lower part of retina and scotoma in upper part of the visual field of the same eye.

Diffuse thinning or diffuse atrophy of the nerve fiber layer can be seen in advanced glaucoma. It is usually difficult to detect on one eye, but when we compare both eyes together, glaucoma atrophy is usually asymmetric and is easily recognized.

\section{Nerve fibre layer defecst and how to image them}

Fundus camera Canon CF-60UV with digital camera Canon EOS 20D for digital picture performing is used. The camera setting of the visual field is 60 degrees and the excitation 
filter for fluorescein angiography with maximal transmission on wave length $480 \mathrm{~nm}$ is used. Flash intensity is performed to F2 level. Camera setting: Lens shutter time is 1/80, ISO 400 and picture quality L /3504×2669 pixels/ - type JPG. Personal computer with operating system Windows XP is connected with a digital camera by the way of a USB connector. Program EOS Viewer Utility is running. This program is attached to a digital camera CD. In this program we create a new folder for each patient with his or her ID, in which we save the pictures.

\subsection{Performing of the digital picture}

The examination is performed is at least in $5 \mathrm{~mm}$ pupil dilation. The patient is looking with his/her examination eye to the camera objective so in the centre of the picture is the central part of the retina. The next step is performing the correct approximation of the fundus camera close to the examination eye, focusing and pressing the shutter of the camera. The performed picture is taken within 1 second and is translate from the camera to the computer so we can examine the picture on the screen.

If the picture is too dark or too light, intensity of the flash is slightly changed and photo is repeated. Usually 3 to 5 pictures are taken from each eye. In full screen program EOS Viewer Utility the best picture is choose and other pictures are deleted.

\subsection{Computer graphics adjustment in program Photoshop CS2}

Original picture is adjusted in the following steps:

a. Downloading of the original picture to the program Photoshop - File/Open (Fig.6, 7)

b. Adjustment of the picture histogram - Image/ Adjustment / Levels - shift of the right, eventually left scroll bar close to the center. (Fig.8, 9)

c. Picture conversion to the monochromatic light-Image / Mode / Gray scale (Fig.10, 11)

d. Adjustment of the contrast- Image / Adjustment / brightness and contrast (Fig. 12)

e. Storing of the adjusted image (Fig. 13)

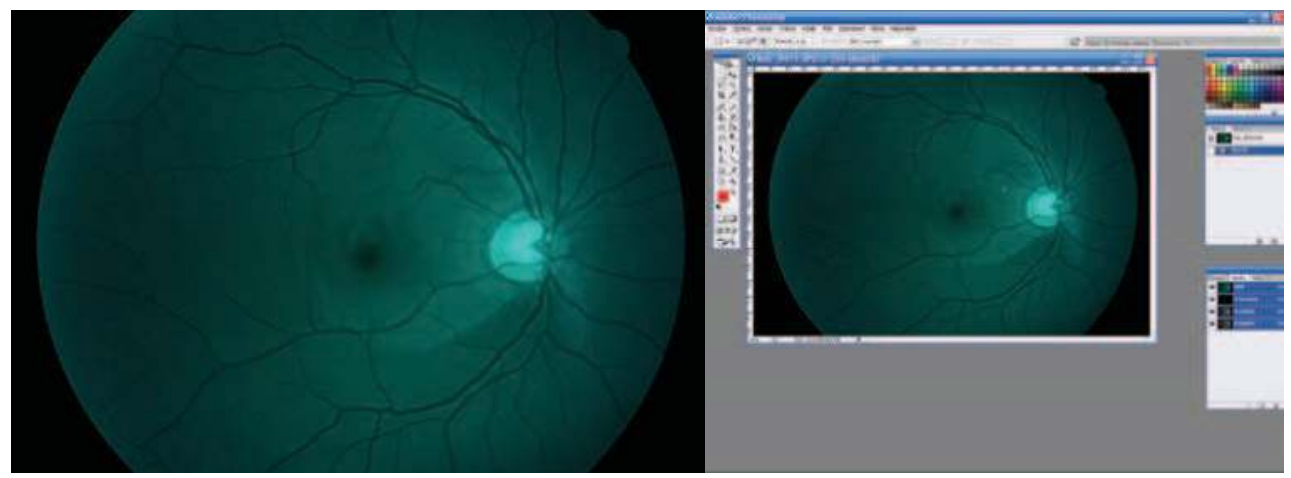

Fig. 6. and 7. Original picture and it s downloading to program Photoshop 

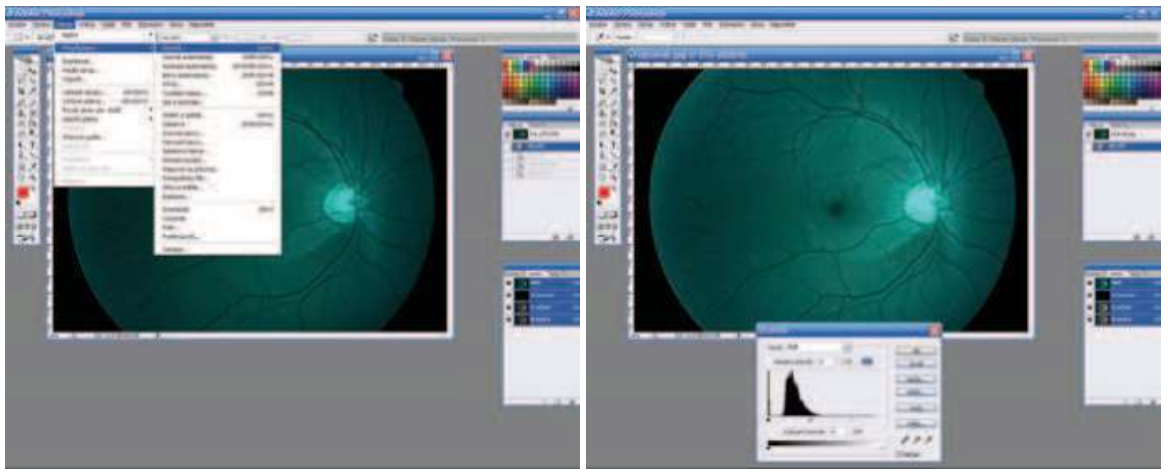

Fig. 8. 9. Histogram picture adjustment

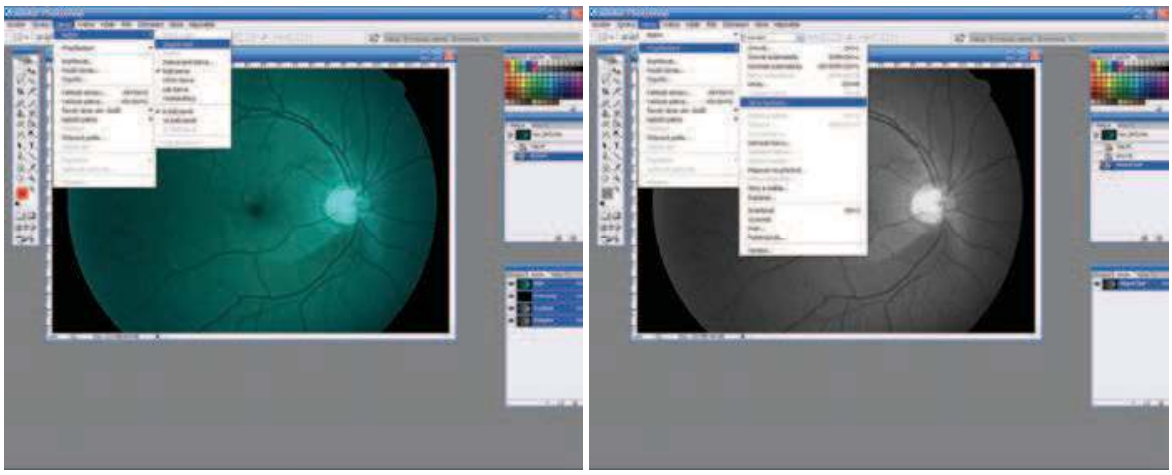

Fig. 10. 11. Picture conversion to monochromatic light

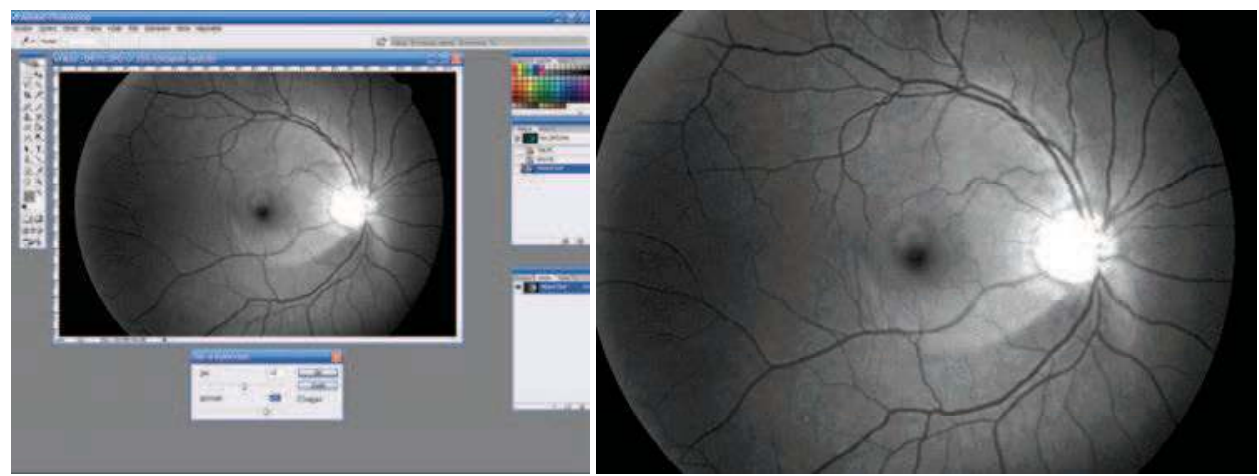

Fig. 12. 13. Brightness, contrast adjustment and picture storage. 


\section{Cases}

\subsection{Case 1}

We would like to present 43 years old man under treatment for pigmentary glaucoma since year 2000. Even before year 2000 there was the visual field scotoma in upper part on the right eye corresponding with nerve fiber layer defect (Fig. 14), left eye optic nerve and visual field were normal. Prostaglandins were select as a first local antiglaucoma therapy. Although intraocular pressure was about 11,0/12,0 mm Hg, in April 2005 we found peripapillary hemorrhage in No 7 on the right eye, on September 2005 there was evident widening of the wedge nerve fiber layer defect in lower part of right eye, scotoma on the upper part of the right eye was getting deeper and wider. Focal defects on upper part of retina on the right eye and on the left eye are also visible. These small defects didn't cause visual field yet. We added local beta blockers to treatment. One year later, in 2006, Intraocular pressure was 16,5/15, $0 \mathrm{~mm} \mathrm{Hg}$. On the both eyes nerve fiber layer defects were similar, also the visual field defects was still on the right eye only, on the left eye was normal visual field. After next 3 years, in 2009, the right eye nerve fiber layer defect and scotoma were still the same extent, but on the left eye we have found peripapillary hemorrhage and the focal nerve fiber layer defect was getting wider (Fig. 15) and scotoma in the upper part of the visual field of the left eye have appeared. We indicated penetrating trabeculectomy on both eyes, et present are the values of intraocular pressure are about $10,0 \mathrm{~mm} \mathrm{Hg}$ on both eye without local therapy.

In this case we tried to demonstrate how the focal nerve fiber defects (without visual field defects) can enlarge to wedge defects of nerve fiber layer corresponding with visual field defects. (Fig.16,17). Very useful are also peripapillary hemorrhages as indicator of the glaucoma progression.

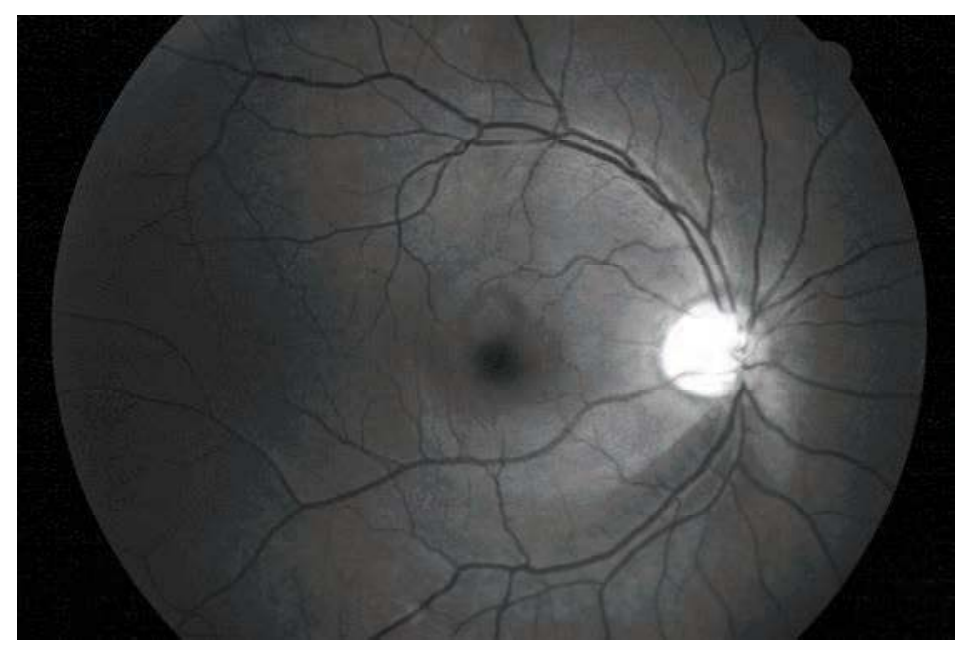

Fig. 14. Right eye: Bellow the optic disc wedge defect corresponding with visual field defect on the upper part. 


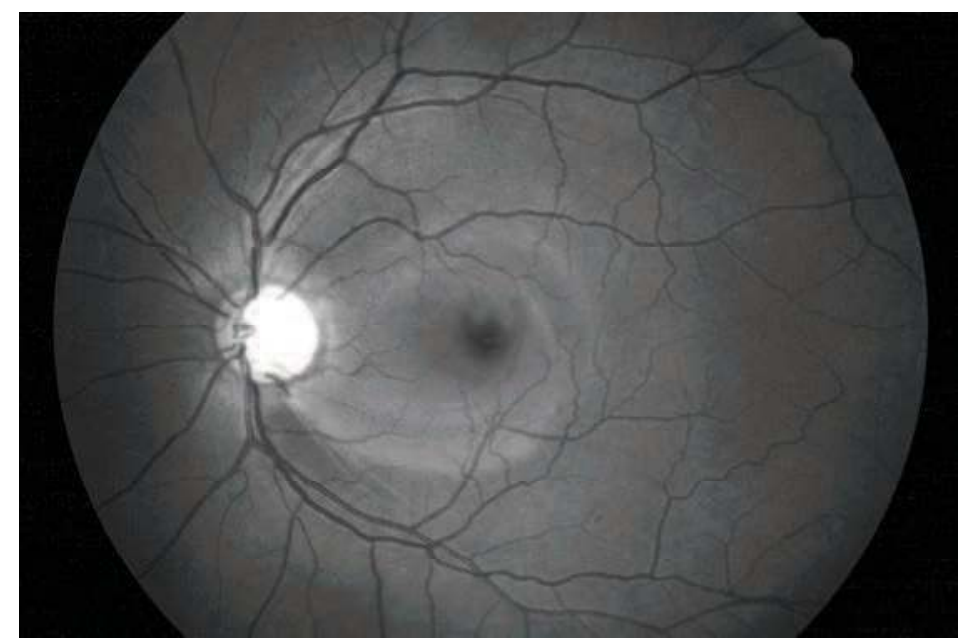

Fig. 15. Left eye: Optic disc splinter hemorrhage on 5 clock. Bellow the optic disc wedge defect
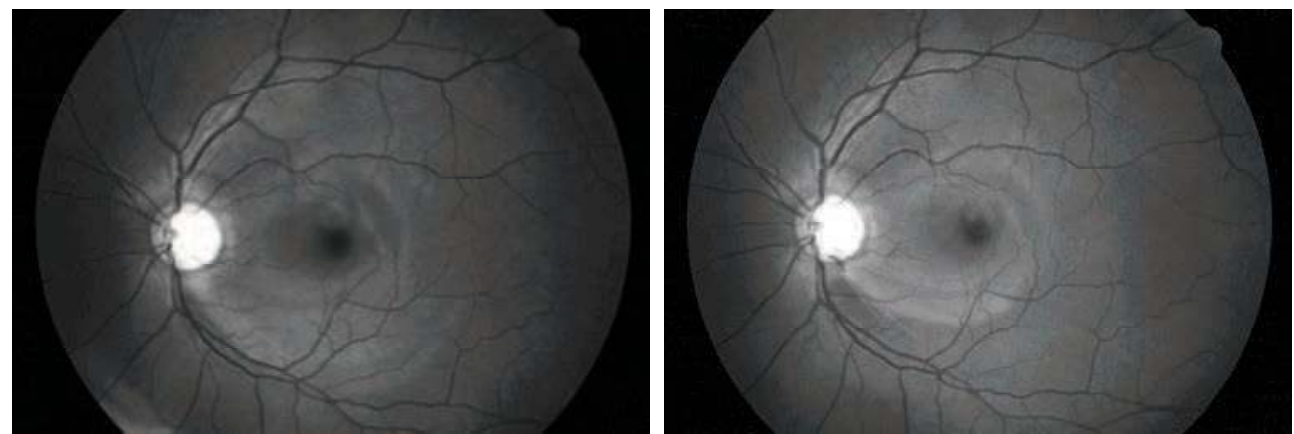

Fig. 16. 17. Left eye: widening of nerve fibre layer defect in lower part of retina in 5 clock position on optic nerve head, which is attending peripapillary hemorrhage. On the left picture (2005) there are only few focal nerve fibre layer defects, on the right picture (2009) peripapillary hemorrhage, wedge defect on the lower part of retina and identical focal defects on the upper part.

\subsection{Case 2}

47 years old man was sending to our service for reasons non proliferative diabetic retinopathy. This man undergo treatment hypertension (blood pressure 150/80 $\mathrm{mm} \mathrm{Hg}$ ) and diabetes mellitus - insulin. 
On retinas of both eyes we have found optic nerve head with normal cupping, vessels with hypertonic changes - narrowing of arteries, dilatation of veins and cross signs. In both retinas was seen dot like hemorrhages. In red free light there were numerous focal nerve fibre layer defects (Fig. 18).

We speculated that nerve fibre layer defects are in consequences with multifocal micro infarcts of optic nerve head in praetrombotic status.

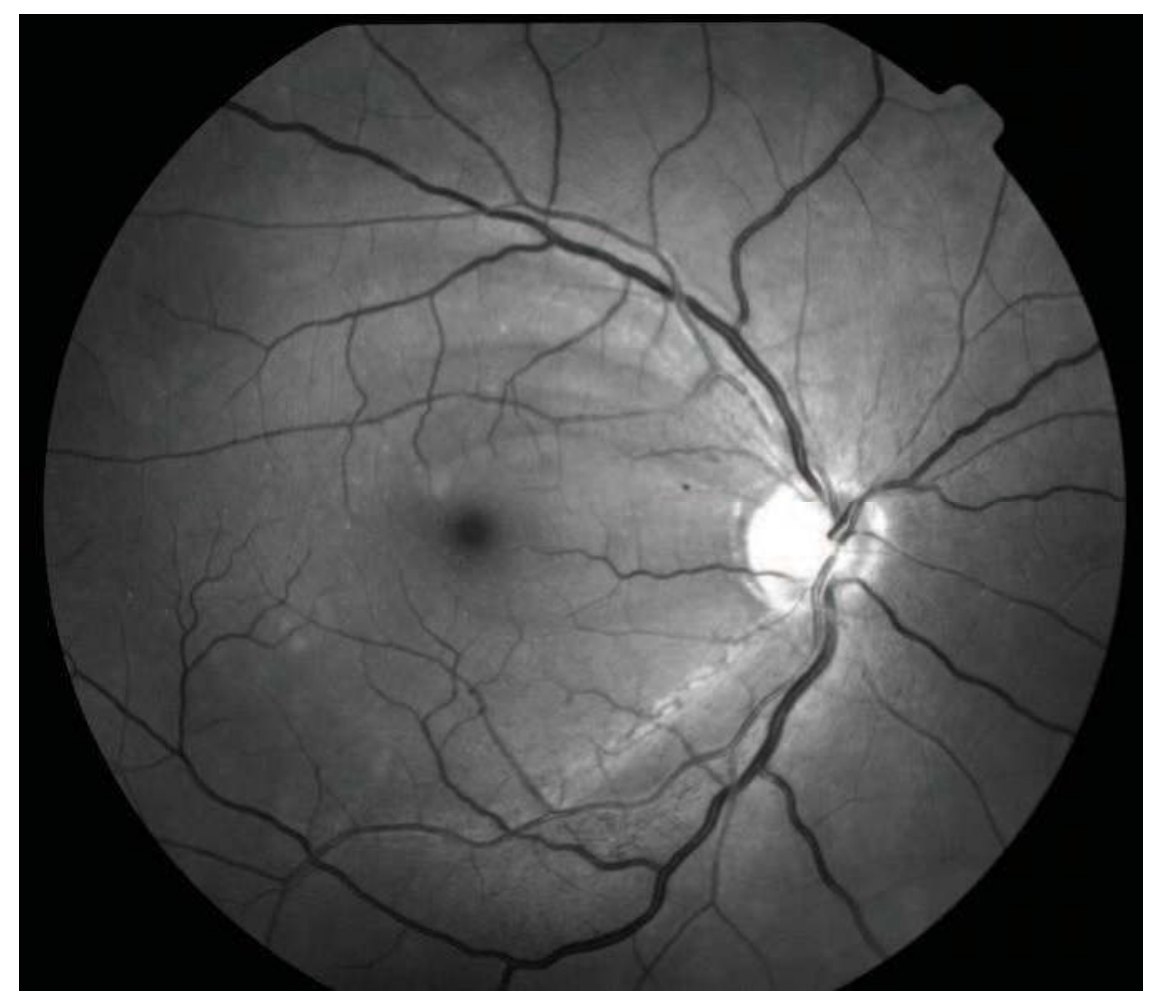

Fig. 18. Dilated veins, cross signs and numerous focal defects of nerve fibre layer 


\section{Discussion}

Nerve fiber layer was firstly described by Vogt in 1913 (Vogt et all., 1913) Half an century later Berhrendt a Wilson (Behrendt et all., 1965) during photo of the retina found, that nerve fiber layer is not visible in the red light, but better visible on the green and blue light. This phenomenon they elucidated by the fact, that blue light does not penetrate through nerve fiber layer, but it is reflected back to the camera in contrast to places with damaged nerve fiber layer and light is absorbed by pigment epithelium of the retina. This is the principle of the contrast between normal and damage areas. Delori and Gradoudas (Delori et all., 1976) founded that best wave length of the light for photography of nerve fiber layer are these from 475 to $520 \mathrm{~nm}$. Rohrschneider (Rohrschneider et all., 1995) recommend for patients with slightly pigmented retinas is useful green-blue filter $470-490 \mathrm{~nm}$, for others green filters 520-540 nm. 15 Airaxinen (Airaxinen et all., 1984) refers about easy detection of nerve fiber layer wide-angle camera with blue monochromatic interference filter.

Nerve fiber layer defects was firstly described by Hoyt (Hoyt et all., 1973). In our national Czech literature published about nerve fiber layer and it s imaging Kurz (Kurz et all., 1956), Kraus (Kraus et all., 1996), Lestak (Lestak et al., 2000).

On our department we found good results with exiting filter for fluorescein angiography with maximal permeability on wave length $480 \mathrm{~nm}$. (Kubena et all., 2008) This filter is usually constant component of the funduscamera. Film frame of the camera we used $60^{\circ}$, which is useful compare with the $30^{\circ}$ visual field test. Nerve fiber layer visibility on native pictures is markedly worse in comparison with subjective examination. That is why we tried to find method of the adjustment of pictures so picture quality was nearly equal to our subjective feeling during biomicroscopy examination. We described method picture adjustment in Photoshop program to achieve this effect.

With compared 30 eyes adjusted photographs of nerve fiber layer pictures with results of Heidelberg Retina Tomography, Laser Polarimetry and Optic Coherence Tomography on each eye. Nerve fiber layer defect were comparable on each method, but in case of thin, early defects adjusted photography was superior other methods.

Benefit of nerve fiber layer digital pictures is there are familiar for ophthalmologists, widerange field and good sensitivity for very thin and early defects.

Disadvantage of the wide-ranged digital pictures is necessity to dilate pupils in taking photos, subjectively evaluation of pictures only, which requires experience of the physicist and impossibility to compare pictures with normative data with sophisticated computer programs.

\section{Conclusion}

Nerve fiber layer and its defects is beneficial to document with digital red free mydriatic fundus camera. Usual fundus camera with exciting filter for fluorescein angiography can be used. Consecutive adjustment digital pictures in Photoshop CS2 improve visibility of nerve fiber layer. The nerve fiber layer defects in this adjustment photos are comparable with this defects detected by recent image methods. Early recognition of focal defects of retinal nerve fiber layer is useful for diagnosis preperimetric stage of glaucoma, its treatment and follow up. 


\section{References}

Airaksinen, PJ., Drance, SM., Douglas, GR. et al.: Diffuse and localized nerve fiber loss in glaucoma. Am J Ophthalmol., 98, 1984, 566 p.

Airaksinen, PJ., Drance, SM., Douglas, GR. et al.: Visual field and retina nerve fiber layer comparisons in glaucoma, Arch Ophthalmol., 103, 1985, 205 p.

Airaksinen, PJ., Nieminen, H., Mustonen, E.: Retina nerve fiber layer photography with a wide-angle fundus kamera, Acta Ophthalmol (Copenh) 60, 1982: 362 p.

Airaksinen, PJ., Tuulonen, A.: Retinal nerve fiber layer evaluation. In Varma, R., Spaeth, GL. (Ed): The optic nerve in glaucoma, Philadelphia, JB Lippincott, 1993, 277-289 p.

Behrendt, T., Wilson, LA.: Spectral reflectance photography of the retina. Am J Ophthalmol 59, 1965.: $1079 \mathrm{p}$.

Behrendt, T., Duane, TD.: Investigation of fundus oculi with spectral reflectance photography. I. Depth and integrity of fundal structures, Arch Ophghalmol., 75, $1966,375 \mathrm{p}$.

Delori, FC., Gradoudas, ES.: Examination of the ocular fundus with monochromatic light. Ann. Ophthalmol., 8, 1976, 703 p.

Hoyt, WF., Frisen, L., Newman, NM.: Funduscopy of nerve fiber layer defects in glaucoma, Incest Ophthalmol., 12, 1973: 814 p.

Kraus, H., Bartosova, L., Hycl, J.: Evaluation of Retinal Nerve Fiber Layer in Glaucoma. I. Introduction and Method. Ces. a slov. Oftal., 52, 1996, 4: 207-209.

Kraus, H., Bartosova, L., Hycl, J.: Evaluation of Retinal Nerve Fiber Layer in Glaucoma. II. Retinal Nerve Fiber Layer Examination and Development of Visual Field Defects in a Prospective Study. Ces. a slov. Oftal., 56, 2000, 3: 149-153.

Kraus, H., Konigsdorfer, E., Ciganek, L.: Nerve fiber bundle defects of the retina and alteration of computer perimetry in initial stages of glaucoma simplex. Cs. Oftal., 41, 1985, 5: 294-298.

Kubena, T., Klimesova, K., Kofronova M., Cernosek P.: Subjective Examination of the Nerve Fiber layer of the Retina and its Evaluation in Healthy eye and in Glaucoma. Ces. a slov. Oftal., 64, 2008, 1: 3-7.

Kubena, T., Klimesova, K., Kofronova M., Cernosek P.: Digital images of the Retinal Nerve Fiber Layer in Healthy Eye and in Glaucoma. Ces. a slov. Oftal., 65, 2009, 1: 3-7.

Kurz, J.: Oftamlo-neurologicka diagnostika, Praha, Statni zdravotnicke nakladatelstvi, 1956, 765.

Lestak J., Pitrova S., Peskova H.: Diagnostika glaukomu vysetrenim vrstvy nervových vlaken. Ces. a slov. Oftal., 56, 2000, 6: 394-400.

Rohrschneider, K., Kruse, F.E., Durk, R.O.: Possibilities for imaging the retina nerve fiber layer sign the SLO. Ophthalmologe, 92, 1995, s 515/520.

Vogt A: Demonstration eines von Rot befreiten Ophthalmoskopierlichtes. Ber. Dtsch. Ophthalm. Ges. Heidelberg 39, 1913: 416.

Vogt A: Die Nervenfaserstreifung der menschlichen Netzhaut mit besonderer Berucksichtigung der Differential-Diagnose gegenuber Pathologischen streifenformigen reflexen (preretinalen Faltelungen), Klin Monatsbl Augenheilkd., 58, 1917: 399. 
Vogt A: Die Nervenfaserzeichnung der menschlichen Netzhaut im rotfreien Licht. Klin Monatsbl Augenheilkd., 66, 1921: 718. 


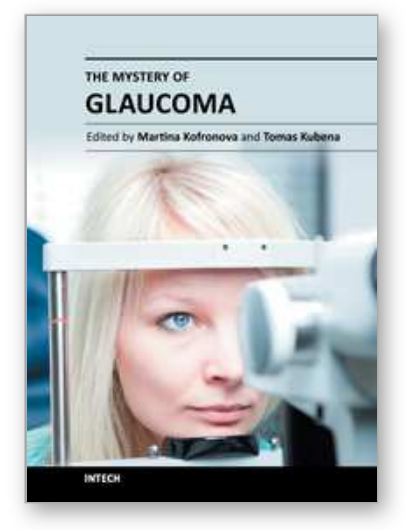

\author{
The Mystery of Glaucoma \\ Edited by Dr. Tomas Kubena
}

ISBN 978-953-307-567-9

Hard cover, 352 pages

Publisher InTech

Published online 06, September, 2011

Published in print edition September, 2011

Since long ago scientists have been trying hard to show up the core of glaucoma. To its understanding we needed to penetrate gradually to its molecular level. The newest pieces of knowledge about the molecular biology of glaucoma are presented in the first section. The second section deals with the clinical problems of glaucoma. Ophthalmologists and other medical staff may find here more important understandings for doing their work. What would our investigation be for, if not owing to the people's benefit? The third section is full of new perspectives on glaucoma. After all, everybody believes and relies - more or less - on bits of hopes of a better future. Just let us engage in the mystery of glaucoma, to learn how to cure it even to prevent suffering from it. Each information in this book is an item of great importance as a precious stone behind which genuine, through and honest piece of work should be observed.

\title{
How to reference
}

In order to correctly reference this scholarly work, feel free to copy and paste the following:

Kubena T., Kofronova M. And Cernosek P. (2011). Nerve Fiber Layer Defects Imaging in Glaucoma, The Mystery of Glaucoma, Dr. Tomas Kubena (Ed.), ISBN: 978-953-307-567-9, InTech, Available from: http://www.intechopen.com/books/the-mystery-of-glaucoma/nerve-fiber-layer-defects-imaging-in-glaucoma

\section{INTECH}

open science | open minds

\section{InTech Europe}

University Campus STeP Ri Slavka Krautzeka 83/A 51000 Rijeka, Croatia Phone: +385 (51) 770447 Fax: +385 (51) 686166 www.intechopen.com

\section{InTech China}

Unit 405, Office Block, Hotel Equatorial Shanghai No.65, Yan An Road (West), Shanghai, 200040, China 中国上海市延安西路65号上海国际贵都大饭店办公楼405单元 Phone: +86-21-62489820

Fax: +86-21-62489821 
(C) 2011 The Author(s). Licensee IntechOpen. This chapter is distributed under the terms of the Creative Commons Attribution-NonCommercialShareAlike-3.0 License, which permits use, distribution and reproduction for non-commercial purposes, provided the original is properly cited and derivative works building on this content are distributed under the same license. 